\title{
Effects of nitrogen deposition on the interaction between an aphid and its host plant
}

\author{
CARALYN B. ZEHNDER ${ }^{1}$ and MARK D. HUNTER ${ }^{2}{ }^{1}$ Institute of Ecology, University \\ of Georgia, Athens, Georgia, U.S.A. and ${ }^{2}$ Department of Ecology and Evolutionary Biology, School of Natural Resources and \\ Environment, University of Michigan, Ann Arbor, Michigan, U.S.A.
}

\begin{abstract}
Anthropogenic increases in nitrogen deposition are impacting terrestrial ecosystems worldwide. While some of the direct ecosystem-level effects of nitrogen deposition are understood, the effects of nitrogen deposition on plant-insect interactions and on herbivore population dynamics have received less attention.

2. Nitrogen deposition will potentially influence both plant resource availability and herbivore population growth. If increases in herbivore population growth outstrip increases in resource availability, then increases in the strength of density dependence expressed within the herbivore population would be predicted. Alternatively, if plant resources respond more vigorously to nitrogen deposition than do herbivore populations, a decline in the strength of density dependence would be expected. No change in the strength of density dependence acting upon the herbivore population would suggest equivalent responses by herbivores and plants.

3. A density manipulation experiment was performed to examine the effect of nitrogen deposition on the interaction between a host plant, Asclepias tuberosa, and its herbivore, Aphis nerii. Aphid maximum per capita growth rate $\left(R_{\max }\right)$, carrying capacity $(K)$, and the strength of density dependence were measured under three nitrogen deposition treatments. The effect of nitrogen deposition on the relationship among these three measures of insect population dynamics was explored.

4. Simulated nitrogen deposition increased aphid per capita population growth, plant foliar nitrogen concentrations, and plant biomass. Nitrogen deposition caused $R_{\max }$ and $K$ to increase proportionally, leading to no overall change in the strength of density dependence. In this system, potential changes in the negative feedback processes operating on herbivore populations following nitrogen deposition appear to be buffered by concomitant changes in resource availability.
\end{abstract}

Key words. Aphis nerii, Asclepias tuberosa, density dependence, density manipulation experiment, global change, herbivory, nitrogen deposition, plant quality.

\section{Introduction}

Anthropogenic increases in nitrogen deposition are important drivers of environmental change (Vitousek et al., 1997; Throop $\&$ Lerdau, 2004). Sources of deposition are mainly transportation, power plants, industry, and agriculture (Driscoll et al., 2003). Current levels of nitrogen deposition range from 0 to $40 \mathrm{~kg} \mathrm{ha}^{-1}$ year $^{-1}$, and in many areas downwind of major urban

Correspondence: Caralyn B. Zehnder, Institute of Ecology, University of Georgia, 1033 DW Brooks Drive, Athens, GA 30606, U.S.A. E-mail: cbzehnder@tamu.edu and agricultural centres, deposition levels approach 30-90 kg ha $^{-1}$ year $^{-1}$ (Van der Eerden et al., 1998; Fenn et al., 2003b). As the human population continues to increase, it is predicted that nitrogen deposition will also increase (Fenn et al., 2003b) with concomitant effects at multiple levels of biological organisation including individuals, populations, communities, and ecosystems (Jefferies \& Maron, 1997; Vitousek et al., 1997; Gotelli \& Ellison, 2002; Aber et al., 2003; Fenn et al., 2003a; Madritch \& Hunter, 2003; Throop \& Lerdau, 2004).

Nitrogen deposition may have positive, negative, or no effects on insect herbivore population dynamics (Throop \& Lerdau, 2004; Throop, 2005). Nitrogen deposition often leads

(C) 2008 The Authors Journal compilation (C) 2008 The Royal Entomological Society 
to increases in foliar nitrogen concentrations and plant biomass (Aber et al., 2003; Fenn et al., 2003a; Throop \& Lerdau, 2004). Because most insect herbivores are nitrogen limited (White, 1993), increases in herbivore densities with increasing levels of nitrogen deposition would be predicted. This prediction assumes that nitrogen deposition does not change plant secondary compounds or alter amino acid profiles, both of which can lead to decreased herbivore performance (Throop \& Lerdau, 2004). Additionally, nitrogen deposition can affect insect herbivores by altering plant or insect community composition (Stevens et al., 2004).

Long-term population dynamics depend, in part, on the strength of density dependence (Hunter, 2001) which can vary in space and time (Cappuccino \& Price, 1995; Harrison \& Cappuccino, 1995). For insect herbivores, variation in the strength of density dependence has been attributed to plant size (Rotem \& Agrawal, 2003), plant genotype (Underwood \& Rausher, 2000), plant resistance traits (Underwood \& Rausher, 2002; Agrawal et al., 2004), and variation in herbivore maximum per capita population growth rate (Agrawal et al., 2004). Currently, it is not possible to predict when to expect strong or weak density dependence, how anthropogenic environmental change will affect its strength, and subsequent effects on insect population dynamics.

Density dependence is often illustrated as the negative relationship between per capita growth rate and population density (Fig. 1). In such diagrams, the $y$-intercept represents the maximum per capita growth rate $\left(R_{\max }\right)$, the $x$-intercept represents carrying capacity $(K)$, and the slope of the line represents the strength of density dependence. How might nitrogen deposition influence the form of this relationship? Figure 1 illustrates three hypothetical scenarios, where the solid lines indicate zero anthropogenic nitrogen deposition and the dotted lines indicate conditions after nitrogen deposition. In all three cases we assume negative density dependence, meaning there is a decrease in per capita population growth as initial density increases (Gotelli, 2001). In Fig. 1a, $R_{\max }$ and $K$ increase proportionally and there is no change in the strength of density dependence after deposition (i.e. the slopes of the lines are the same). This is similar to fig. 1 (lines A and C) in Agrawal et al. (2004). In Fig. 1b, $R_{\max }$ increases faster than $K$ increases, and the strength of density dependence increases. In Fig. 1c, $K$ increases faster than $R_{\max }$ increases, and the strength of density dependence decreases.

While there are relatively few studies of the effects of nitrogen deposition per se on insect herbivores (Throop \& Lerdau, 2004), there have been many reported effects of nitrogen fertilisation on insect herbivores (Mattson, 1980; Kyto et al., 1996; Cisneros \& Godfrey, 2001; Nevo \& Coll, 2001; Tsai \& Wang, 2001; Stiling \& Moon, 2005). Typically, nitrogen fertilisation rates in such experiments far exceed any predicted nitrogen deposition rates. Experiments examining the effects of nitrogen deposition try to mimic current deposition levels and use nitrogen deposition rates no greater than $100 \mathrm{~kg} \mathrm{ha}^{-1}$ year $^{-1}$ (Carreiro et al., 2000; van der Wal et al., 2003; Throop \& Lerdau, 2004). Higher levels of nitrogen application, usually $200 \mathrm{~kg} \mathrm{ha}^{-1}$ year $^{-1}$ or greater (Jansson \& Smilowitz, 1986), are used in many fertilisation experiments and mimic modern agricultural practices. In a review of nitrogen fertilisation experiments conducted by Kyto et al. (1996), nitrogen fertilisation typically led to an increase in aphid abundance and performance. However, other insect guilds either showed no increase in abundance or performance or showed a negative response (Kyto et al., 1996). Nitrogen fertilisation has also been linked with increased insect density, shorter development time, higher survival rates, increased insect mass, higher fecundity, and higher $R_{\max }$ (Mattson, 1980; Cisneros \& Godfrey, 2001; Nevo \& Coll, 2001; Tsai \& Wang, 2001; Stiling \& Moon, 2005). However, other studies have found negative or no effects of nitrogen fertilisation on insect abundance or performance (Bethke et al., 1998; Casey \& Raupp, 1999; Muller et al., 2005).

There is no a priori reason to assume that insect population growth rate and environmental carrying capacity should respond in concert to environmental change. To explore this further, a density manipulation experiment was performed to examine the effect of nitrogen deposition on the interaction between a host plant, Asclepias tuberosa, and its herbivore, Aphis nerii. Aphid maximum per capita growth rate $\left(R_{\max }\right)$, carrying capacity $(K)$, and the strength of density dependence were measured under three nitrogen deposition treatments and the effect of nitrogen deposition on the relationship among these three measures of insect population dynamics was explored. (a)

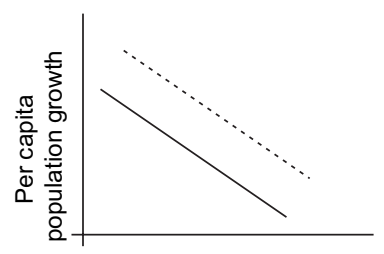

(b)

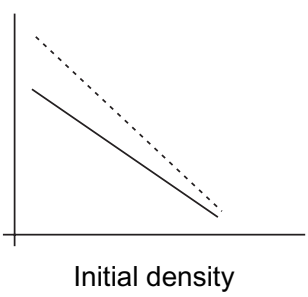

(c)

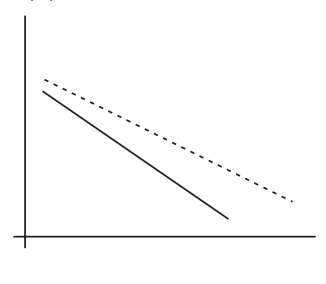

Fig. 1. Three hypothetical scenarios showing the effect of nitrogen deposition on the relationship between initial density and per capita population growth rate. The solid line indicates zero deposition conditions and the dotted line represents conditions after nitrogen deposition. The slope of the line is a measure of the strength of density dependence and negative density dependence is assumed in all three scenarios. (a) The maximum population growth rate, $R_{\max }$ (the $y$-intercept), and the carrying capacity, $K$ (the $x$-intercept), increase proportionally and there is no change in the strength of density dependence. (b) $R_{\max }$ increases faster than $K$, and therefore the strength of density dependence increases. (c) $K$ increases faster than $R_{\max }$ and the strength of density dependence decreases. 


\section{Materials and methods}

\section{Study species}

Aphis nerii Boyer de Fonscolombe (Hemiptera: Aphididae), the milkweed-oleander aphid, is an aposematic phloem-feeding specialist of milkweed (Asclepias spp) and oleander [Nerium oleander L. (Apocynaceae)] that reproduces parthenogenetically (Rothschild et al., 1970; Hall \& Ehler, 1980). In August 2003, one A. nerii individual was collected near Gainesville, Florida. The aphid colony (clone) was initiated from this one individual. In the laboratory, aphid colonies were kept on Asclepias syriaca at low densities. Asclepias seeds were obtained from a seed distributor (Butterfly Encounters, Dublin, CA).

Experiments were conducted in a temperature and light controlled walk-in growth chamber (September-October 2005). Grow lights on timers (LD 16:8 h) provided heat and light; daytime and night-time temperatures were $34.0 \pm 2.4$ and $24.0 \pm 0.5^{\circ} \mathrm{C}$ respectively, which is within the range normally experienced by both aphid and plant species. Temperature was measured and recorded using $\mathrm{HOBO}^{\circledR}$ data loggers (Onset Computer Corporation, Bourne, MA). The host-plant species used in this experiment was Asclepias tuberosa, a milkweed species native to Georgia. All seedlings were potted in small ( $0.04 \mathrm{~m}$ radius) plastic pots, and the genotype(s) of the seedlings was unknown. All seedlings were 4 weeks old and the same size at the start of the experiment (12-15 cm in height, 10-12 leaves per seedling). Nitrogen deposition levels and aphid densities were assigned randomly to plants. All potted plants were placed individually in cages constructed from $710 \mathrm{ml}$ Ziploc containers and organza netting over wire frames. Plants were rotated and watered daily.

\section{Nitrogen deposition}

Three levels of nitrogen were applied: 0,25 , and $40 \mathrm{~kg} \mathrm{ha}^{-1}$ year $^{-1}$. These levels fall within the range of nitrogen deposition levels experienced in the U.S.A. (Ollinger et al., 1993; Throop $\&$ Lerdau, 2004). Because this experiment was carried out in small pots (0.04 $\mathrm{m}$ radius), the amount of nitrogen in the form of ammonium nitrate $\mathrm{NH}_{4} \mathrm{NO}_{3}$ was calculated based on an area of $0.005 \mathrm{~m}^{2}$. For the three nitrogen deposition levels $0,0.036$, and $0.057 \mathrm{~g}$ of $\mathrm{NH}_{4} \mathrm{NO}_{3}$ were needed respectively. These were divided into four applications over the course of 3 weeks. For each application, $25 \%$ of the appropriate amount of $\mathrm{NH}_{4} \mathrm{NO}_{3}$ was dissolved in deionised water and $20 \mathrm{ml}$ solution was applied to each plant with a pipette. Nitrogen application occurred on day 1 (6 September 2005), day 8 (13 September 2005), day 15 (20 September 2005), and day 22 (27 September 2005).

\section{Aphid density manipulation}

Six aphid densities were established $(0,1,5,10,15$, and 20 aphids per plant), with five replicates of each nitrogen deposition treatment by aphid density combination for a total of 90 experimental plants $(6$ aphid densities $\times 3$ nitrogen treatments $\times 5$ repli- cates $=90$ experimental plants). On day 14 (19 September 2005), two adult apterous aphids were placed on each plant (except for those plants receiving the $0 \mathrm{aphid} /$ plant treatment). The aphids were allowed to reproduce overnight, and the following day the adults were removed and the offspring thinned to the appropriate densities. After 14 days (until day 28), spanning approximately two to three aphid generations, total population and number of alates (winged aphids) were counted on each plant. Because the aphid densities reached such high levels, it was not possible to count all of the aphids on all plants in 1 day. Therefore, on day 28 (3 October 2005) half of the aphids were counted and the rest were counted on day 29 (4 October 2005). Treatments were divided evenly between the 2 days of counting and population growth rates were adjusted accordingly for the extra day of growth (below). After aphids were counted, above-ground plant biomass was harvested. Each plant was clipped at the base of its stem and then rinsed with deionised water to remove any aphid honeydew. Plants were dried at $64^{\circ} \mathrm{C}$ in a drying oven (Lab-line, Dubuque, IA), weighed with a Mettler balance (Mettler Toledo, Greifensee, Switzerland) and the top five leaves were ground into a fine powder using a ball mill grinder (Spex Certiprep, Metuchen, NJ). For carbon $(\mathrm{C})$ and nitrogen $(\mathrm{N})$ analysis, ground samples were weighed into tin capsules with a Mettler UMT2 microbalance (Mettler Toledo) and analysed with a Carlo Erba NA 1500 CHN analyser (Carlo Erba, Milan, Italy).

\section{Statistical analysis}

Aphid per capita growth rate was calculated on each plant by subtracting the natural $\log$ of the initial density $\left(N_{1}\right)$ from the natural $\log$ of the final density $\left(N_{2}\right)$ divided by the number of days that aphids $\left(t_{2}-t_{1}\right)$ were on the plants: $\left(\ln N_{2}-\ln N_{1}\right) /\left(t_{2}-t_{1}\right)$. The strength of density dependence was determined for each nitrogen deposition level by finding the slope of the regression of per capita growth rate versus initial density. $R_{\max }$ (maximum population growth rate) for each nitrogen deposition level was found by determining the $y$-intercept of each regression equation, and $K$ (carrying capacity) was found by determining the $x$-intercept for each equation. Although non-linear declines in per capita growth rate with population density have been reported (Sibly et al., 2005), non-linear parameters provided no improvement in models, confirming that linear density dependence predominates in this aphid species (Agrawal et al., 2004).

Rates of aphid population growth were compared among deposition treatments using analysis of covariance (ANCOVA) with nitrogen deposition as a class variable and initial density as a covariate. ANCOVA is an appropriate method for comparing slopes and intercepts of regression lines (Sokal \& Rohlf, 1995), and therefore it allows us to compare $R_{\max }, K$ and the strength of density dependence among the three nitrogen deposition treatments. Effects of nitrogen deposition on the strength of density dependence were assessed by the significance of the interaction term between nitrogen deposition and initial density. This functions as a comparison of slopes (Fig. 1). Final plant biomass, foliar nitrogen concentrations, and the proportion of alate aphids produced were compared among deposition treatments using ANCOVA as above. Tukey's honest significant difference tests were conducted 
to compare among treatment means. All analyses were conducted using SAS version 8.2 for windows (SAS Institute, Cary, NC). Residuals were checked for normality and met assumptions of normality except in one case; proportion alate data were arcsinesquare root transformed prior to analysis.

\section{Results}

Aphid per capita population growth decreased as initial aphid density increased, confirming the presence of negative density dependence (Fig. 2, Table 1). Nitrogen deposition led to increases in aphid $R_{\max }, K$ and per capita population growth (Fig. 2, Tables 1 and 2). However, the strength of density dependence did not differ significantly among nitrogen deposition levels [Table 1 (interaction term), Table 2]. The proportion of alate aphids that were produced increased with initial aphid density (Fig. 3: density $F_{1,61}=35.57, P<0.001$ ). However, nitrogen deposition had no effect on the proportion of alate aphids produced (Table 2: nitrogen $F_{261}=0.44, P=0.648$, nitrogen $\times$ density $F_{2,62}=0.32, P=0.727$ ).

Asclepias tuberosa foliar nitrogen concentrations increased with nitrogen deposition and decreased with initial aphid density (Fig. 4: nitrogen $F_{2,71}=18.25, P<0.001$, density $F_{1,71}=17.21$, $P<0.001$, nitrogen $\times$ density $F_{271}=0.27, P=0.766$ ).

Final biomass of $A$. tuberosa plants increased with nitrogen deposition whereas initial aphid density had no effect on final plant biomass (Fig. 5: nitrogen $F_{274}=19.14, P<0.001$, density $F_{1,74}=0.34$, $P=0.564$, nitrogen $\times$ density $F_{2,74}=2.58, P=0.082$ ).

\section{Discussion}

In this system, simulated nitrogen deposition leads to proportional increases in aphid per capita growth rate and carrying capacity (Fig. 2), as well as increases in plant foliar nitrogen concentration and biomass (Figs 4 and 5). The proportional increase in aphid $R_{\max }$ and $K$ results in no change in the strength of density dependence, corresponding to the scenario illustrated in Fig. 1a. In this case, the increase in aphid population growth is balanced by the increase in environmental carrying capacity. Not surprisingly, negative density dependence (Fig. 2) was exhibited under all experimental conditions. Previous research in this system found decreases in aphid per capita survival and fecundity with increasing density on four milkweed species in-

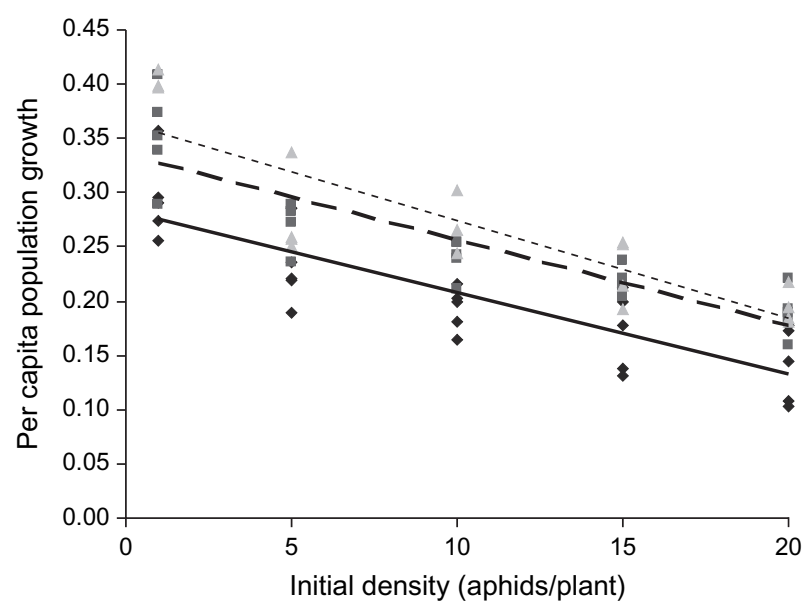

Fig. 2. The effect of initial Aphis nerii density on A. nerii per capita population growth among three nitrogen deposition levels on Asclepias tuberosa. Each line represents the regression of initial aphid density on per capita population growth ( $n=25$ for each nitrogen deposition level). The solid dark line and diamonds represent $0 \mathrm{~kg} \mathrm{ha}^{-1}$ year $^{-1}$ nitrogen. The dark dashed line and squares represent $25 \mathrm{~kg} \mathrm{ha}^{-1}$ year $^{-1}$ nitrogen, and the light dashed line and triangles represent $40 \mathrm{~kg} \mathrm{ha}^{-1} \mathrm{year}^{-1}$ nitrogen.

cluding A. tuberosa (Zehnder \& Hunter, 2007). Likewise, Agrawal (2004) reported that $A$. nerii exhibited negative density dependence on 17 out of 18 milkweed species.

As Agrawal et al. (2004) have shown, $R_{\max }$ and $K$ do not always vary in concert. In their experiments working with $A$. nerii on Asclepias syriaca and other milkweed species, they found no proportional change in $K$ with variation in $R_{\max }$. As a consequence, any increase in $R_{\max }$ was associated with an increase in the strength of density dependence, the scenario illustrated in Fig. 1b. Agrawal et al. (2004) did not explicitly manipulate plant quality within a single host-plant species, as was done in the present study. By manipulating plant quality via nitrogen deposition, it has been shown in the present study that it is possible to increase $R_{\max }$ and at the same time increase $K$. Therefore, under these conditions, $R_{\max }$ is not an accurate predictor of the strength of density dependence. Further research is needed to determine when maximum per capita population growth rate and carrying capacity are directly proportional, like in the present study, and when they do not scale proportionally, such as found by Agrawal et al. (2004).

Table 1. The influence of nitrogen deposition and initial Aphis nerii density on per capita growth rate of the aphid population over two to three generations on Asclepias tuberosa.

\begin{tabular}{|c|c|c|c|c|c|}
\hline & Type III sum of squares & d.f. & Mean square & $F$-value & $P$ \\
\hline Nitrogen deposition & 0.0224 & 2 & 0.0112 & 9.32 & 0.0003 \\
\hline Initial aphid density & 0.2022 & 1 & 0.2022 & 168.24 & $<0.0001$ \\
\hline Nitrogen deposition $\times$ initial density & 0.0011 & 2 & 0.0006 & 0.48 & 0.6209 \\
\hline Error & 0.0733 & 61 & 0.0012 & & \\
\hline
\end{tabular}

The non-significant interaction between initial aphid density and nitrogen deposition indicates that the strength of density dependence did not differ among nitrogen deposition treatments. 
Table 2. The effect of nitrogen deposition on the maximum per capita population growth rate $\left(R_{\max }\right)$, carrying capacity $(K)$, strength of density dependence (b), and proportion alate of Aphis nerii on its host plant Asclepias tuberosa.

\begin{tabular}{lllll}
\hline Nitrogen deposition $\left(\mathrm{kg} \mathrm{ha}^{-1}\right.$ year $\left.^{-1}\right)$ & $R_{\max }$ & $K$ & $b$ & Proportion alate \\
\hline 0 & $0.2829(0.012)^{\mathrm{a}}$ & $29.504(2.71)^{\mathrm{a}}$ & $-0.00753(0.001)$ & $0.104(0.02)^{\mathrm{a}}$ \\
25 & $0.3352(0.011)^{\mathrm{b}}$ & $35.124(2.98)^{\mathrm{b}}$ & $-0.00787(0.001)$ & $0.109(0.02)^{\mathrm{a}}$ \\
40 & $0.3647(0.017)^{\mathrm{b}}$ & $32.407(3.38)^{\mathrm{b}}$ & $-0.00904(0.001)$ & $0.111(0.02)^{\mathrm{a}}$ \\
\hline
\end{tabular}

Data represent the means of 25 replicates followed by standard errors in parentheses. Different letters within columns denote significantly different means under Tukey's test $\left(R_{\max }, K\right.$, proportion alate).

It is interesting to note that within a single herbivore-plant study system, A. nerii-Asclepias, examples of variation in the strength of density dependence (Agrawal et al., 2004) and examples of no variation in the strength of density dependence (this study) have been documented. A possible explanation for the discrepancy between these two studies is that certain factors, such as temperature, affect insect herbivores more strongly than they affect plant resource availability, at least on a short-term basis. Therefore, temperature variation leads to variation in aphid $R_{\max }$, but leads to no change in carrying capacity, causing variation in the strength of density dependence (Agrawal et al., 2004). Similarly, variation in host plant species will affect herbivore $R_{\max }$, but not $K$, when equally-sized host plants are chosen (Agrawal et al., 2004). The 18 host-plant species examined by Agrawal et al. (2004) were of similar age and size, meaning that plant resource availability was roughly similar among all hostplant species, or $K$ was held constant. However, the Asclepias species varied in quality, including variation in nitrogen and water content, cardenolide concentration, and trichome density (Agrawal, 2004; Agrawal et al., 2004). This variation in plant quality, but not plant quantity, leads to variation in aphid $R_{\max }$ and this leads to variation in the strength of density dependence.

In this experiment, nitrogen deposition led to increased aphid per capita population growth rate and increased foliar nitrogen concentrations, confirming a link between foliar nitrogen content and A. nerii $R_{\max }$ (Agrawal, 2004). Similarly, in a nitrogen fertilisation experiment using cotton-melon aphids, Aphis gossypii, a positive relationship was found between foliar nitro-

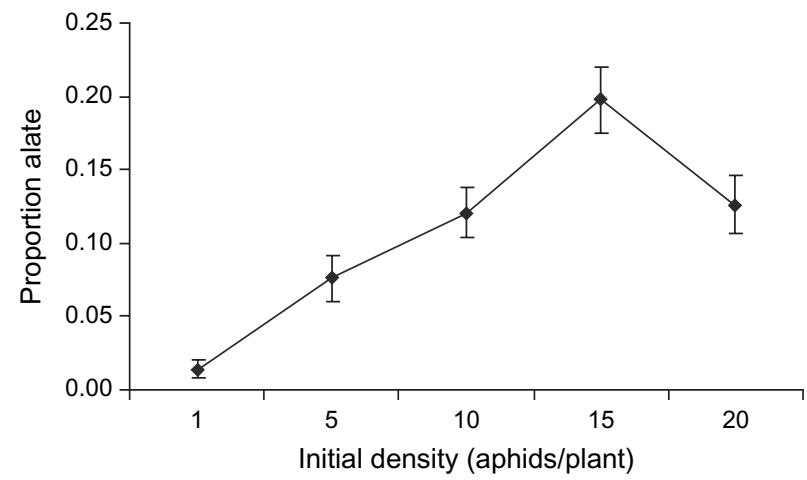

Fig. 3. The effect of initial Aphis nerii density on the proportion alate (winged aphids) present after 2 weeks on Asclepias tuberosa (bars are means of 15 values \pm 1 standard error). ANCOVA density $F_{1,61}=35.57$, $P<0.0001$; nitrogen, NS (not significant); nitrogen $\times$ density, NS. gen concentrations and insect performance (Nevo \& Coll, 2001). Such relationships have been documented for many other insect herbivores (Mattson, 1980), arguing for frequent nitrogen limitation among insect herbivores (White, 1993). While nitrogen addition typically leads to an increase in aphid population growth rates, this is not always the case. In a field experiment examining the effects of fertiliser addition and predator exclusion on Aphis jacobaeae, an aphid-specialist of ragwort, there was no effect of fertilisation on aphid density (Muller et al., 2005). However, foliar quality was not measured in this experiment; therefore it is possible that the fertilisation treatment did not affect plant quality or that there was an increase in plant defensive compounds. It is also possible that natural enemies had a larger impact on aphid population growth than did plant productivity (Muller et al., 2005).

In the present study, nitrogen deposition increased both plant quality (Fig. 4) and quantity (Fig. 5) and similar results have been documented for a variety of plant species (Throop \& Lerdau, 2004). For example, nitrogen deposition was found to increase seedling nitrogen content and growth rate for five out of six annual species in a California grassland community (Cleland et al., 2006). In the present study, as initial aphid density increased, foliar nitrogen concentrations

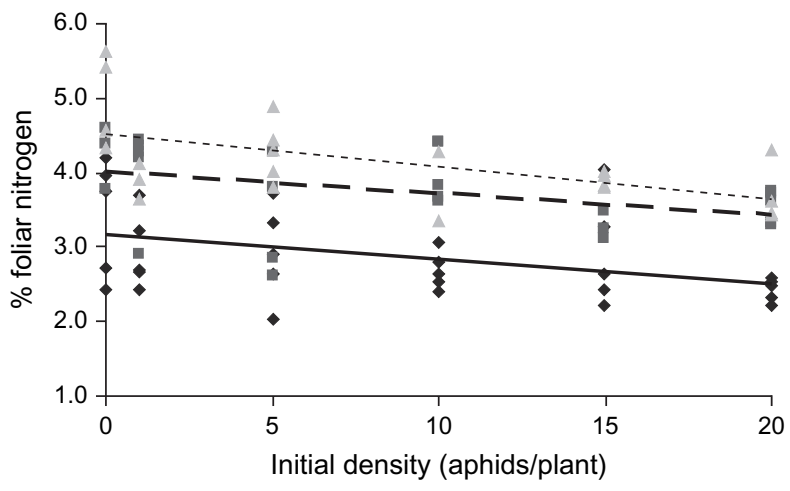

Fig. 4. The effect of initial Aphis nerii density on Asclepias tuberosa percentage foliar nitrogen among three nitrogen deposition levels. Each line represents the regression of initial aphid density on percentage foliar nitrogen ( $n=30$ for each nitrogen deposition level). The solid dark line and diamonds represent $0 \mathrm{~kg} \mathrm{ha}^{-1}$ year $^{-1}$ nitrogen. The dark dashed line and squares represent $25 \mathrm{~kg} \mathrm{ha}^{-1}$ year $^{-1}$ nitrogen, and the light dashed line and triangles represent $40 \mathrm{~kg} \mathrm{ha}^{-1}$ year $^{-1}$ nitrogen. ANCOVA nitrogen $F_{2,71}=18.25, P<0.0001$; density $F_{1,71}=17.21, P<0.0001$; nitrogen $\times$ density, NS (not significant). 


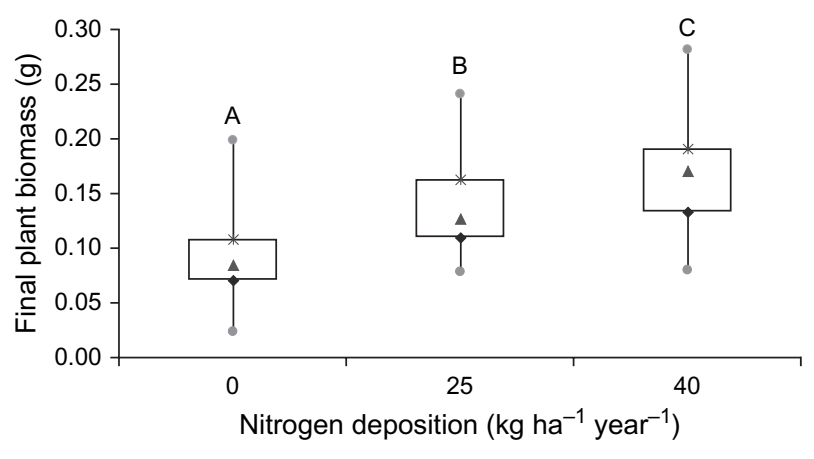

Fig. 5. Boxplots showing the effect of nitrogen deposition on Asclepias tuberosa final dry biomass (plots are means of 30 values \pm 1 standard error). Initial aphid density had no effect on final plant biomass, so data are pooled by nitrogen treatment. The top and bottom points in each plot are the maximum and minimum values respectively. The tops and bottoms of the boxes are the lower and upper quartiles for each nitrogen treatment. The triangle within each box represents the median. Different letters above plots indicate significant differences among treatment means. ANCOVA nitrogen $F_{2,74}=19.14, P<0.0001$; density, NS (not significant); nitrogen $\times$ density, NS.

decreased, but there was no effect of aphid density on plant biomass. This result suggests an imperfect, or complex, link between nitrogen availability and Asclepias biomass. In a comparable study examining the effects of nitrogen deposition and herbivory on common ragweed, simulated nitrogen deposition led to an increase in plant biomass and foliar nitrogen concentrations. Additionally, neither aphid nor beetle herbivory reduced plant shoot biomass; however there were negative effects of insect herbivory on root and seed biomass (Throop, 2005).

In the present experiment, nitrogen deposition caused an increase in insect herbivore densities. This has important implications for both crop and forest insect pests, especially if nitrogen deposition leads to an increase in the rate or severity of herbivore outbreaks. Recent work has suggested that nitrogen deposition is linked to increases in outbreak frequency of the monophagous heather beetle, Lochmaea suturalis, on Calluna vulgaris in the Netherlands (Bobbink et al., 1998). In the northeastern U.S.A., there are hotspots of nitrogen deposition located in high elevation forests (Driscoll et al., 2003) with the potential to facilitate insect outbreaks.

Only one pair of species was studied in this experiment, and only over a short time period under controlled laboratory conditions. As a result, it is not clear at present how results from the present study relate to dynamics in the field. Nonetheless, there is a long and distinguished history of using laboratory experiments to study population dynamics (Birch, 1953; Huffaker, 1958; Ayala, 1969). In fact, much of current population theory is based on such experiments (Speight et al., 1999). There is still a lack of long-term data examining the continuing impacts of nitrogen deposition on plant and herbivore dynamics. Moreover, it is important to consider higher trophic levels (Hunter, 2001; Muller et al., 2005) and determine how predation and parasitism rates change under nitrogen deposition.
In this study, simulated nitrogen deposition increased aphid per capita population growth, plant foliar nitrogen concentrations, and plant biomass. Nitrogen deposition increased the rate of insect population growth and increased plant biomass such that there was no change in the strength of density dependence. In the system used, potential changes in the negative feedback process operating on herbivore populations following nitrogen deposition appear to be buffered by concomitant changes in resource availability.

\section{Acknowledgements}

We thank M. Parris, S. Scott, and A. Whittaker for laboratory assistance. We thank B. Ball, S. Spires, K. Wickings, H. Wearing, and two anonymous referees for their helpful comments and suggestions.

\section{References}

Aber, J.D., Goodale, C.L., Ollinger, S., Smith, M.L., Magill, A.H., Martin, M.E. et al. (2003) Is nitrogen deposition altering the nitrogen status of northeastern forests? Bioscience, 53, 375-389.

Agrawal, A.A. (2004) Plant defense and density dependence in the population growth of herbivores. American Naturalist, 164, 113-120.

Agrawal, A.A., Underwood, N. \& Stinchcombe, J.R. (2004) Intraspecific variation in the strength of density dependence in aphid populations. Ecological Entomology, 29, 521-526.

Ayala, F.J. (1969) Experimental invalidation of principle of competitive exclusion. Nature, 224, 1076-1078.

Bethke, J.A., Redak, R.A. \& Schuch, U.K. (1998) Melon aphid performance on chrysanthemum as mediated by cultivar, and differential levels of fertilization and irrigation. Entomologia Experimentalis et Applicata, 88, 41-47.

Birch, L.C. (1953) Experimental background to the study of the distribution and abundance of insects. 3. The relation between innate capacity for increase and survival of different species of beetles living together on the same food. Evolution, 7, 136-144.

Bobbink, R., Hornung, M. \& Roelofs, J.G.M. (1998) The effects of airborne nitrogen pollutants on species diversity in natural and seminatural European vegetation. Journal of Ecology, 86, 717-738.

Cappuccino, N. \& Price, P.W. (ed.) (1995) Population Dynamics. Academic Press, San Diego, California.

Carreiro, M.M., Sinsabaugh, R.L., Repert, D.A. \& Parkhurst, D.F. (2000) Microbial enzyme shifts explain litter decay responses to simulated nitrogen deposition. Ecology, 81, 2359-2365.

Casey, C.A. \& Raupp, M.J. (1999) Supplemental nitrogen fertilization of containerized azalea does not affect performance of azalea lace bug (Heteroptera: Tingidae). Environmental Entomology, 28, 998-1003.

Cisneros, J.J. \& Godfrey, L.D. (2001) Midseason pest status of the cotton aphid (Homoptera: Aphididae) in California cotton: is nitrogen a key factor? Environmental Entomology, 30, 501-510.

Cleland, E.E., Peters, H.A., Mooney, H.A. \& Field, C.B. (2006) Gastropod herbivory in response to elevated $\mathrm{CO}_{2}$ and $\mathrm{N}$ addition impacts plant community composition. Ecology, 87, 686-694.

Driscoll, C.T., Whitall, D., Aber, J.D., Boyer, E., Castro, M., Cronan, C. et al. (2003) Nitrogen pollution in the Northeastern United States: sources, effects, and management options. Bioscience, 53, 357-374.

Fenn, M.E., Baron, J.S., Allen, E.B., Rueth, H.M., Nydick, K.R., Geiser, L. et al. (2003a) Ecological effects of nitrogen deposition in the Western United States. Bioscience, 53, 404-420. 
Fenn, M.E., Haeuber, R., Tonnesen, G.S., Baron, J.S., Grossman-Clarke, S., Hope, D. et al. (2003b) Nitrogen emissions, deposition, and monitoring in the Western United States. Bioscience, 53, 391-403.

Gotelli, N.J. (2001) A Primer of Ecology. Sinauer Associates, Sunderland, Massachusetts.

Gotelli, N.J. \& Ellison, A.M. (2002) Nitrogen deposition and extinction risk in the northern pitcher plant, Sarracenia purpurea. Ecology, 83, 2758-2765.

Hall, R.W. \& Ehler, L.E. (1980) Population ecology of Aphis nerii Homoptera, Aphididae on oleander. Environmental Entomology, 9, 338-344.

Harrison, S. \& Cappuccino, N. (1995) Using density manipulation experiments to study population regulation. Population Dynamics (ed. by N. Cappuccino and P. W. Price) pp. 131-147. Academic Press, San Diego, California.

Huffaker, C.B. (1958) Experimental studies on predation: dispersion factors and predator-prey oscillations. Hilgardia, 27, 343-383.

Hunter, M.D. (2001) Multiple approaches to estimating the relative importance of top-down and bottom-up forces on insect populations: experiments, life tables, and time-series analysis. Basic and Applied Ecology, 2, 295-309.

Jansson, R.K. \& Smilowitz, Z. (1986) Influence of nitrogen on population parameters of potato insects: abundance, population growth, and within-plant distribution of the green peach aphid, Myzus persicae. Environmental Entomology, 15, 49-55.

Jefferies, R.L. \& Maron, J.L. (1997) The embarrassment of riches: atmospheric deposition of nitrogen and community and ecosystem processes. Trends in Ecology \& Evolution, 12, 74-78.

Kyto, M., Niemela, P. \& Larsson, S. (1996) Insects on trees: population and individual response to fertilization. Oikos, 75, 148-159.

Madritch, M.D. \& Hunter, M.D. (2003) Intraspecific litter diversity and nitrogen deposition affect nutrient dynamics and soil respiration. Oecologia, 136, 124-128.

Mattson, W.J. (1980) Herbivory in relation to plant nitrogen-content. Annual Review of Ecology and Systematics, 11, 119-161.

Muller, C.B., Fellowes, M.D.E. \& Godfray, H.C.J. (2005) Relative importance of fertiliser addition to plants and exclusion of predators for aphid growth in the field. Oecologia, 143, 419-427.

Nevo, E. \& Coll, M. (2001) Effect of nitrogen fertilization on Aphis gossypii (Homoptera: Aphididae): variation in size, color and reproduction. Journal of Economic Entomology, 94, 27-32.

Ollinger, S., Aber, J.D., Lovett, G.M., Millham, S.E., Lathrop, R.G. \& Ellis, J.M. (1993) A spatial model of atmospheric deposition for the Northeastern U.S. Ecological Applications, 3, 459-472.

Rotem, K.A. \& Agrawal, A.A. (2003) Density dependent population growth of the two-spotted spider mite, Tetranychus urticae, on the host plant Leonurus cardiaca. Oikos, 103, 559-565.
Rothschild, M., Euw, J.V. \& Reichste, T. (1970) Cardiac glycosides in the oleander aphid, Aphis nerii. Journal of Insect Physiology, 16, 1141-1145.

Sibly, R.M., Barker, D., Denham, M.C., Hone, J. \& Pagel, M. (2005) On the regulation of populations of mammals, birds, fish, and insects. Science, 309, 607-610.

Sokal, R.R. \& Rohlf, F.J. (1995) Biometry: The Principles and Practice of Statistics in Biological Research, 3rd edn. W.H. Freeman \& Company, New York.

Speight, M.R., Hunter, M.D. \& Watt, A.D. (1999) The Ecology of Insects: Concepts and Applications. Blackwell Science, Oxford.

Stevens, C.J., Dise, N.B., Mountford, J.O. \& Gowing, D.J. (2004) Impact of nitrogen deposition on the species richness of grasslands. Science, 303, 1876-1879.

Stiling, P. \& Moon, D.C. (2005) Quality or quantity: the direct and indirect effects of host plants on herbivores and their natural enemies. Oecologia, 142, 413-420.

Throop, H.L. (2005) Nitrogen deposition and herbivory affect biomass production and allocation in an annual plant. Oikos, 111, 91-100.

Throop, H.L. \& Lerdau, M.T. (2004) Effects of nitrogen deposition on insect herbivory: implications for community and ecosystem processes. Ecosystems, 7, 109-133.

Tsai, J.H. \& Wang, J.J. (2001) Effects of host plants on biology and life table parameters of Aphis spiraecola (Homoptera: Aphididae). Environmental Entomology, 30, 44-50.

Underwood, N. \& Rausher, M.D. (2000) The effects of host-plant genotype on herbivore population dynamics. Ecology, 81, 1565-1576.

Underwood, N. \& Rausher, M. (2002) Comparing the consequences of induced and constitutive plant resistance for herbivore population dynamics. American Naturalist, 160, 20-30.

Van der Eerden, L., De Vries, W. \& Van Dobben, H. (1998) Effects of ammonia deposition on forests in the Netherlands. Atmospheric Environment, 32, 525-532.

Vitousek, P.M., Aber, J.D., Howarth, R.W., Likens, G.E., Matson, P.A., Schindler, D.W. et al. (1997) Human alteration of the global nitrogen cycle: sources and consequences. Ecological Applications, 7, 737-750.

van der Wal, R., Pearce, I., Brooker, R., Scott, D., Welch, D. \& Woodin, S. (2003) Interplay between nitrogen deposition and grazing causes habitat degradation. Ecology Letters, 6, 141-146.

White, T.C.R. (1993) The Inadequate Environment: Nitrogen and the Abundance of Animals. Springer, New York.

Zehnder, C.B. \& Hunter, M.D. (2007) A comparison of maternal effects and current environment on vital rates of Aphis nerii, the milkweedoleander aphid. Ecological Entomology, 32, 172-180.

Accepted 17 August 2007 